\title{
Application of Multisim Simulation Software in Power supply Design
}

$$
\text { Renbo } \mathrm{Xu}^{1,2, \mathrm{a}^{*}} \text {, Shaoyi } \mathrm{Li}^{1, \mathrm{~b}} \text { and Jinfeng } \mathrm{Li}^{1, \mathrm{c}}
$$

${ }^{1}$ School of artificial intelligence, Nanchang Institute of Science and Technology Nanchang, 330108, China

${ }^{2}$ Physics and Microelectronics Institute, Central South University Changsha 410083, China

a1310079831@qq.com, b10968369@qq.com, '524892454@qq.com

* The corresponding author

\section{Keywords: Multisim simulation; Power supply design; Circuit simulation; Application research}

\begin{abstract}
The article analyzes the problems in the current electronic technology course teaching and experimental training. On this basis, it explores the application of Multisim circuit simulation teaching in the power design course. The simulation technology can make the analysis of electronic circuit accurately and quickly completed on the computer and overcome the limitations of the components and instruments of the laboratory, it also breaks through the limitation of time and space. This paper focuses on the innovative application and skill of Multisim simulation software in power supply design, which has great help to the design of power supply.

At present, the traditional classroom teaching in vocational colleges is a common phenomenon. Teachers impart some abstract and theoretical knowledge to the students. The complicated theoretical knowledge and traditional teaching methods make the students be afraid of the electronic technology, so that have no willing to learn it actively in class. Although we have mastered a little circuit principle in class, we do not have a deep understanding of the electronic circuit knowledge, which leads to a weariness of learning and a loss of interest in the course of Electronic Technology.The virtual simulation experiment system based on Multisim is helpful to promote teachers to improve teaching methods, stimulate students' interest in learning, improve teaching effect, and improve students' ability to analyze and solve problems. On the basis of students' own ability, they can effectively develop their subjective initiative and develop their creative potential, which is conducive to the matching of practical training equipment and actual production equipment in higher vocational colleges and universities, so as to achieve the purpose of cultivating and training students with advanced, sophisticated and high-tech practical techniques.
\end{abstract}

\section{Simulation Teaching Practice of Multisim Power Supply Circuit}

In order to verify the role of Multisim simulation in teaching practice, the comparative teaching was carried out in the course of Electronic Technology. Multimedia Multisim simulation teaching was used in the experimental class, added with the experimental training of physical equipment and the simulation practice in the computer room. While the ordinary class carries out regular theory teaching and the experimental training of the physical equipment.In the learning process of the experimental class, first of all, from studying the use and characteristic analysis of each component to the circuit analysis and function research of the course, the Multisim software is used as far as possible to guide the explanation. Then the students are trained to use Multisim software to design simulation, to discuss a little more in-depth problem for theoretical consolidation, and finally to use physical experimental equipment for skills training.For example, when teaching the design of alarm circuit for traffic lights, we first use computer to simulate the real laboratory workbench, let students observe the experimental results, for example, stimulate students be interested in classroom teaching through demonstration. After a semester of comparative teaching, the general class and the experimental class that implemented the Multisim circuit simulation teaching received the practical training examination and the final examination with the same test paper.Through the questionnaire investigation, the examination of the experiment training and the analysis of the final examination results, the implementation of Multisim circuit simulation in the teaching of Electronic Technology 
effectively solves the problems existing in the current course of Electronic Technology, which effectively supplementing the shortage of experimental training equipment and promoting the positive influence of beginners. Furthermore, it enables the course of Electronic Technology full of creativity and fun from theory teaching to experimental practice teaching, so that effectively arouses the students' interest in learning and promote their acquisition of theoretical knowledge and practical skills. Circuit drawing analysis is as shown in Fig. 1, Buck-Boost control circuit voltage mode

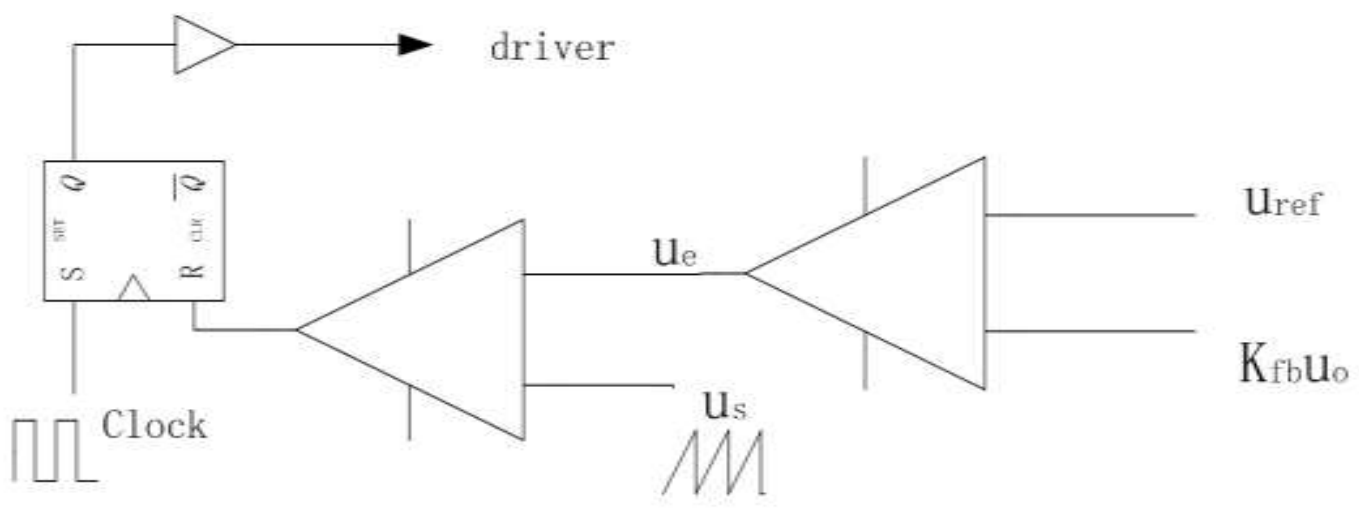

Figure 1. Finite Buck-Boost Voltage mode control schematic diagram

As shown in Fig. 1, the output voltage feedback signal $K_{f b} u_{O}$ is compared with the reference voltage signal $^{u_{r e f}}$, and the error voltage signal $u_{e}$ is obtained. The error voltage signal is added to the inverse phase of the pulse width modulation comparator, and the positive phase input voltage signal $^{u_{s}}$ is input. The output signal of the comparator is connected to the reset end of the $R S$ trigger,The clock signal Clock is connected to the position terminal of the $R S$ trigger. After the signal of the $Q_{\text {end signal of }} R S$ trigger is passed through the driver, the switch tube driving signal is generated, the output voltage feedback signal $K_{f b} u_{O}$ rises, If the error voltage signal $u_{e}$ is smaller than $u_{s}$, the comparator generates a high level to reset the $R S$ trigger, and the switch ends until the arrival of a periodic clock signal.

\section{Use Multisim for Carrying Out the Power Supply Design to Stimulate Learning Interest}

Through multimedia teaching, students can learn theory and culture intuitively and arouse students' desire for knowledge. Then through practice, they could change the concept of the world into the real world. Therefore, only when students have the consciousness to seek for the reasons, can they be stimulated by their subjective initiative to explore with courage, thus giving full play to the subjective initiative of autonomous learning, so that promote the understanding of what they have learned. At the same time, when students understand the knowledge, there will be a joy of success in their hearts, which will promote their efficient and active learning with interest.It is helpful to break through the routine model of experimental teaching, improve the students' ability to analyze and solve problems and their ability of innovation. The target orientation of higher vocational education lies in a senior technical applied talent training in the front line of the market, which emphasizing the training of applied skills. Therefore, thus the experimental training teaching is particularly important. In the course of Electronic Technology, students are usually divided into groups, and complete a specific task in a limited time, with short time and heavy task, everyone is busy measuring the results of the experiment, yet can not carry out in-depth experimental research. Multisim provides a powerful component library and virtual instruments. Students can operate quickly in experiments, and they can easily use virtual instruments to troubleshoot problems in experiments. Even if the time is not enough, the experiment can be brought to the outside class or even the dormitory for further research, which can improve the students' ability to analyze and solve 
problems and to innovate.

\section{The Experiment Teaching with Multisim Can Eliminate the Interference of the Environment and the Instrument Itself.}

The positive effects of the experimental results, such as electromagnetic radiation, temperature, light, humidity and other external environments, will have an important impact on the electronic components of the physical equipment, which will cause changes in the performance parameters of the electronic components. Long working hours of electronic instruments is also a loss of components.In addition, the instrument itself generally also has systematic errors, so for physical equipment, a series of errors will often result in the failure of the experimental results or a wrong result, which for or the students that studying the e-course for the first time, will have a great negative impact. But Multisim is a virtual experiment software, which realizes the application of virtual experiment circuit and equipment.The formation of this kind of equipment is mainly based on the software program. The software program is not affected by the external environment, and the virtual device is also not affected by the external environment and the system error. Therefore, the virtual experiment is always correct, which can eliminate the negative effect and realize the positive effect on the experiment result for the learners of the electronic technology course. The circuit drawing analysis is shown in Fig. 2、3. In order to verify the anti-interference ability of CUK converter's improved feedforward control of OCC , The 10V 、100 Hz sinusoidal signal and $12 \mathrm{~V}$ 、 $25 \mathrm{~Hz}$ square wave signal are respectively superimposed on the input voltage of the system, and the waveform of output voltage is observed. It can be seen that the variation of input voltage has no effect on the output voltage waveform, and the dynamic performance of the system is very well, which shows that the improved feedforward control strategy of OCC has a good ability to resist input interference.

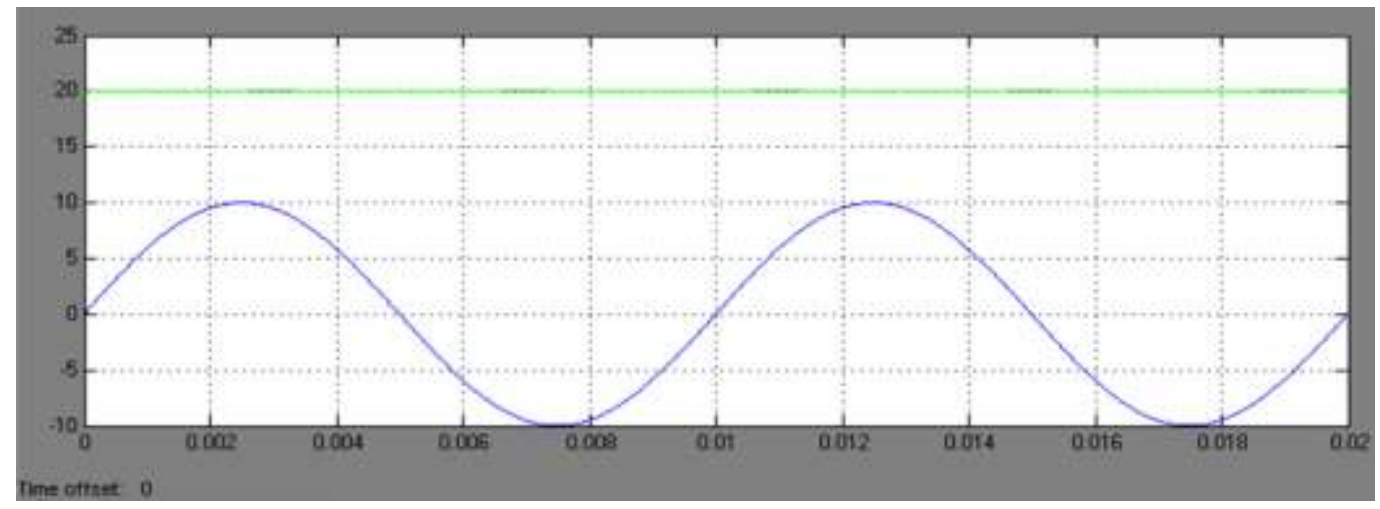

Figure 2. Finite Working waveform of input voltage superimposed with 10V 、100Hz sinusoidal signal

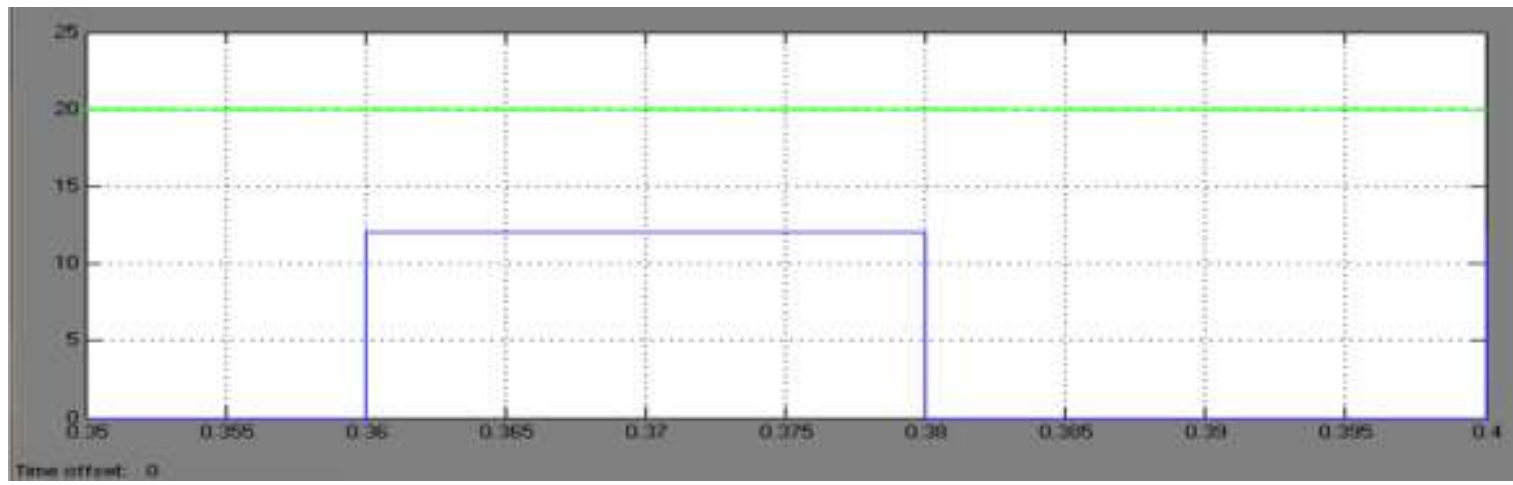

Figure 3. Finite Working waveform of input voltage superimposed $12 \mathrm{~V} 、 25 \mathrm{~Hz}$ square wave signal 


\section{Conclusion}

Simulation software is used to assist the teaching of power technology course, so that the theory can be verified at any time. The virtual electronic technology experiment with simulation software breaks through the limitation of time and space of the traditional experiment and can flexibly arrange the experiment time according to different hobbies and needs. It is an effective supplement to the electronic technology experiment. As long as students have the basic knowledge of electronic technology and certain ability of software operation, they can effectively use virtual experiments to carry out relevant experiments and achieve good experimental results. At the same time, mastering circuit simulation software is also an effective tool for electronic system analysis and design, which lays a solid foundation for future work.

\section{Acknowledgements}

This research was financially supported by Key scientific research projects of Jiangxi Provincial Department of Education (Grant NO. GJJ161218, ). Scientific research start-up funding(Grant NO. NGRCZX-17-01). Nanchang DME photoelectric engineering key laboratory(Grant NO. NCZDSY--004).

\section{References}

[1] Xing Xiaorui. The exploration and practice of the teaching of "simulated electronic technology experiment" [J] Journal of Electrical and Electronic Teaching, 2013, 35(1) :86-87.

[2] Li Zhijun, Chen Wanpei.The experimental teaching reform of the simulation circuit [J] Experimental Science and Technology, 2015, 11(4) :78-80.

[3] Xie Dong, Guan Zhengqiang. Design and exploration of comprehensive experimental project of electronic technology curriculum [J] Experimental Science and Technology, 2015,11 (4) :101-104.

[4] Han Shunjie, Jiang Changhong.Research and practice of open operation management mode of college students' innovation base [J] Experimental Technology and Management, 2013,30 (6) : 119-121.

[5] Yang Yi, Xu Peng.Electronic design competition and practical teaching reform [J] Laboratory Research and Exploration, 2014, 32(4):172-175.

[6] Yao Yingying, Wei Wei. Exploration of relevance teaching mode of electric basic experimental class [J].Journal of Electrical and Electronic Teaching, 2013,35 (3) :69-71.

[7] Qian Xiaoming. Exploration and practice of open management mechanism of university laboratory [J].Experimental Technology and Management, 2013,30 (11) :40-43.

[8] Xiao Kan, Yishi, Yan Guoping. Exploration and practice of innovative electric-electronic all-open experimental teaching mode [J].Laboratory Research and Exploration, 2015,29 (4) :79-82.

[9] Wang Gesi, Zhao Yanfeng. Research and practice of the experimental curriculum system of analog electronic technology[J] Experimental Science and Technology, 2014, 10(5):99-102.

[10]M. Gallant. Guide to Rigid-flex Design. Printed Circuit Design and Manufacture[M]. Education Press 2016, 23(10):30-33. 